\title{
Compatibilization of PET/PS blends through SMA and PMPI dual compatibilizers
}

\author{
M.-Y. Ju, F.-C. Chang* \\ Institute of Applied Chemistry, National Chiao Tung University, Hsinchu, Taiwan
}

Received 26 November 1998; received in revised form 5 March 1999; accepted 17 May 1999

\begin{abstract}
In this study, dual compatibilizers composed of styrene maleic anhydride random copolymer (SMA-8 wt.\% MA) and poly[methylene (phenylene isocyanate)] (PMPI) have demonstrated to effectively compatibilize the immiscible and incompatible blends of poly(ethylene terephthalate) (PET) and polystyrene (PS). SMA with low MA content is totally miscible with PS to make the PS phase quasi-functionalized, so that PMPI has the chance to contact and react with PET and SMA simultaneously to form PET-co-PMPI-co-SMA copolymers at the interface. These desired copolymers are able to anchor along the interface and serve as efficient compatibilizers. The compatibilized blends, depending on the quantity of dual compatibilizers employed, exhibit higher viscosity, finer phase domain, and improved mechanical properties. Moreover, the crystallization behavior of the PET component in these compatibilized blends has been affected. C 1999 Elsevier Science Ltd. All rights reserved.
\end{abstract}

Keywords: Poly(ethylene terephthalate); Polystyrene; Styrene maleic anhydride

\section{Introduction}

It is well known that non-reactive graft or block copolymers can be successfully employed as compatibilizers in compatibilizing those immiscible and incompatible polymer blends [1-3]. These copolymers are considered as interfacial agents of the blends because they tend to concentrate at the interface ideally and act as emulsifiers. However, they may not have the chance to migrate effectively to the interface or even form micelles within matrices. In addition, most graft or block copolymers suitable as compatibilizers usually require separate preparation steps to produce, very few are commercially readily available. To overcome these shortcomings, reactive blending technique has been introduced as an alternative in compatibilizing incompatible polymer blends. The reactive blending technique utilizes a copolymer containing functional groups that are able to react with one (or more) of the constituent component to form graft or block copolymers during melt blending. These in situ-formed copolymers tend to stay at the interface as the reaction between functional groups occurs at the interface, and thus act as effective compatibilizers between two immiscible polymers. For blends of polymers containing functional groups, reactive compatibilization has been

\footnotetext{
* Corresponding author. Tel.: +886-3-5712121-56502; fax: +886-35723764 .
}

regarded as a better approach to improve the compatibility [4-18]. Copolymers or couplers containing anhydride [4-8] or epoxy [9-14] groups are the most often employed reactive compatibilizers for polymers containing amine or carboxyl terminal groups. They are successful in improving the interfacial adhesion and mechanical properties. There are other functional groups used in reactive blending, such as carboxyl $[15,16]$ and oxazoline $[17,18]$.

Poly(ethylene terephthalate) (PET) and polystyrene (PS) are immiscible and incompatible that has been well recognized. As PS does not contain the necessary functional group, adding a functionalized polymer miscible with PS to react with PET becomes an attractive strategy. Maa and Chang [11] employed the styrene-glycidyl methacrylate copolymer (SG) as a reactive compatibilizer for the PET/ PS blends, and resulted in better interfacial adhesion and improved mechanical properties. Maleic anhydride (MA) possesses a good reactivity toward the terminal amine groups of polyamides [4-8]. However, the reaction between MA and the terminal groups of polyesters is unlikely or insignificant without the presence of a catalyst, only the secondary physical interaction is expected. Based on these understandings, we attempted to add the commercially available styrene-maleic anhydride copolymer (SMA, 8 wt.\% MA) into the PET/PS blends to make the PS phase quasi-functionalized. Therefore, the coupling approach [19] can be carried out in extruder compounding. A 
PET<smiles>O=C(O)c1ccc(C(=O)OCCO[TlH])cc1</smiles>

PS<smiles>CCCC(C)c1ccccc1</smiles>

SMA<smiles>CC(C)C1C(=O)OC(=O)C1C(CC(C)(C)C)CC(C)(C)C</smiles>

PMPI

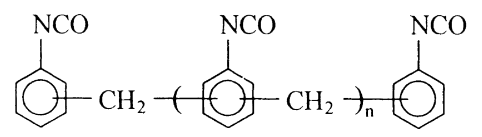

Scheme 1. Chemical structures of materials.

multifunctional epoxy resin has been employed in this PET/ PS/SMA blending system as a reactive coupler in our previous investigation [20]. The epoxy resin possessing multifunctional groups can react with PET and SMA at interface simultaneously to form in situ PET-co-epoxy-coSMA copolymers during melt blending. The dual compatibilizers consisting of SMA and epoxy resin result in reduced domain size of the dispersed phase and enhance the mechanical properties of the PET/PS blends effectively [20].

Pernice et al. [21] demonstrated that blends of polyamide and poly(phenylene ether) (PPE) containing 0.5-3.0 wt.\% of an organic diisocyanate such as $4,4^{\prime}$-(diphenyl methane) diisocyanate or 2,4-toluene diisocyanate have a good balance of mechanical, thermal, and processing properties. Koseki et al. [22] reported that PET film coated with PPE can be compatibilized by methylene diisocyanate (MDI) as a coupling agent and resulted in substantial improvement of chemical and heat resistance. A commercially available oligomeric isocyanate, poly[methylene (phenylene isocyanate)] (PMPI), has been demonstrated as an efficient coupler to improve compatibility of blends of polyamide 6 (PA6) and PPE [23], resulting in substantial improvements in mechanical properties. In this study, PMPI is employed as an effective reactive coupler in the PET/PS/SMA blends.
We intend to report their specific compatibility and correlation with their resultant morphological, thermal, and mechanical properties.

\section{Experimental}

\subsection{Materials}

PET, Shin PET, I.V. = 1.0, was kindly donated by the Shinkong Synthetic Fibers Inc. of Taiwan. PS, Maxiglac 125, was obtained from the B.C. Chem. Co. of Taiwan. The SMA copolymer containing 8 wt.\% MA, Dylark 232, was purchased from the ARCO Chemical Co. The reactive coupler, poly[methylene (phenylene isocyanate)] (PMPI) containing $31.5 \%$ NCO group, was obtained from the BASF Chemical Co. PMPI has a melt viscosity of $200 \mathrm{cps}$ measured at $25^{\circ} \mathrm{C}$ and has the average functional groups per chain of 2.7. The structures of materials are presented in Scheme 1.

\subsection{Blend preparation}

Prior to extruder compounding, the PET pellets were dried at $120^{\circ} \mathrm{C}$, and PS and SMA were dried at $90^{\circ} \mathrm{C}$ for over $24 \mathrm{~h}$ in separate ovens. PMPI was dried at $60^{\circ} \mathrm{C}$ for $2 \mathrm{~h}$ before using. All blends were prepared in a $30 \mathrm{~mm}$ corotating intermeshing twin-screw extruder $(L / D=36$, SinoAlloy Machinery Inc. of Taiwan) with a rotational speed of $250 \mathrm{rpm}$. The extruded pellets were then dried in a vacuum oven and molded into 1/8 in. standard ASTM specimens by using an Arburg 3-oz injection-molding machine. The detailed processing conditions for extrusion and injection molding are listed in Table 1.

\subsection{Rheological properties}

To verify potential chemical reactions among PET, SMA, and PMPI based on the viscosity increase, torque versus time measurements were carried out in a Brabender PlastiCorder, type PLD 651. The temperature was controlled at $285^{\circ} \mathrm{C}$ and the rotational speed was set at $30 \mathrm{rpm}$. The capillary rheological measurements of the blends and matrices were also carried out at $285^{\circ} \mathrm{C}$ using a capillary rheometer ( $L / D=40$, orifice radius $=0.02$ in. $)$ from Kayeness Co. of USA, Model Galaxy V.

Table 1

Processing conditions

\begin{tabular}{|c|c|c|c|c|c|c|c|c|c|c|c|c|}
\hline Stage & 1 & 2 & 3 & 4 & 5 & 6 & 7 & 8 & 9 & Die & Nozzle & Mold \\
\hline \multicolumn{13}{|c|}{ A. Extrusion condition: } \\
\hline Temp. $\left({ }^{\circ} \mathrm{C}\right)$ & 210 & 260 & 270 & 275 & 280 & 280 & 285 & 285 & 285 & 280 & & \\
\hline \multicolumn{13}{|c|}{ B. Injection condition: } \\
\hline Temp. $\left({ }^{\circ} \mathrm{C}\right)$ & 275 & 280 & 285 & & & & & & & & 290 & 80 \\
\hline
\end{tabular}




$$
\begin{aligned}
& \mathrm{R}-\mathrm{NCO}+\mathrm{R}^{\prime}-\mathrm{COOH} \longrightarrow\left[\mathrm{R}-\stackrel{\mathrm{H}}{\mathrm{N}}-\stackrel{\mathrm{O}}{\mathrm{C}}-\mathrm{O}-\stackrel{\mathrm{O}}{\mathrm{C}}-\mathrm{R}^{\prime}\right] \\
& \stackrel{-\mathrm{CO}_{2}}{\longrightarrow} \mathrm{R}-\stackrel{\mathrm{H}}{\mathrm{I}}-\stackrel{\mathrm{I}}{\mathrm{C}}-\mathrm{R}^{\prime}
\end{aligned}
$$

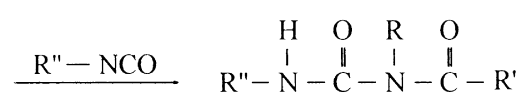

$$
\begin{aligned}
& \mathrm{R}-\mathrm{NCO}+\mathrm{R}^{\prime}-\mathrm{OH} \rightleftharpoons \mathrm{R}-\stackrel{\mathrm{H}}{\mathrm{N}} \stackrel{\mathrm{I}}{\mathrm{C}}-\mathrm{O}-\mathrm{R}^{\prime}
\end{aligned}
$$

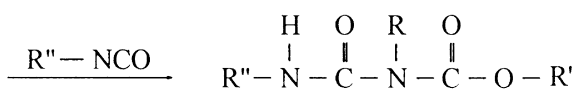

Scheme 2. The simplified reaction mechanisms for isocyanate with carboxyl and hydroxyl.

\subsection{Thermal properties}

Thermal properties of blends and pure components were studied by differential scanning calorimetry (DSC) with an average weight of 5-10 mg on a DSC instrument model DSC 910s from TA Co. of USA. The measurements were made between 30 and $300^{\circ} \mathrm{C}$ at a scanning rate of $10^{\circ} \mathrm{C} / \mathrm{min}$. The sample was heated at $300^{\circ} \mathrm{C}$ for $5 \mathrm{~min}$ and then cooled down in determining the crystallization peak temperature $\left(T_{\mathrm{c}}\right)$ and the crystallization temperature range $\left(\Delta T_{\mathrm{c}}\right)$ of the PET component in the blend. After the cooling treatment, this same sample was heated immediately to measure glass transition temperatures $\left(T_{\mathrm{g}}\right)$ of PET and PS, and melting peak temperature $\left(T_{\mathrm{m}}\right)$, melting temperature range $\left(\Delta T_{\mathrm{m}}\right)$, and heat of fusion of $\operatorname{PET}\left(\Delta H_{\mathrm{f}, \mathrm{PET}}\right)$.

\subsection{Scanning electron microscopies (SEM)}

The morphologies were examined by a SEM, Model S570 , Hitachi Co. of Japan from cryogenically fractured specimens in the plane perpendicular to flow direction of injection molding. Samples were etched with chloroform to dissolve the PS phase out of the blends. The cryogenically fractured surfaces of specimens were coated with thin film of gold to prevent charging.

\subsection{Mechanical properties}

Tensile tests were conducted at ambient conditions using an Instron Universal Testing Machine, Model 4201, according to the ASTM D638 method. The crosshead speed was $5 \mathrm{~mm} / \mathrm{min}$. Unnotched Izod impact strengths were measured at ambient conditions according to the ASTM D256 method, by an Impact Tester from TMI Co. of USA, Model 43-1.

\section{Results and discussion}

\subsection{Chemistry}

A reactive copolymer or a small multifunctional molecule can be considered as a non-specific type in situ compatibilizer because the structure and quantity of the eventually formed copolymers will vary with the content of the reaction group, temperature, time, and mixing efficiency. Several low-molecular-weight multifunctional coupling agents have been demonstrated as excellent reactive compatibilizers for many blending systems in our previous reports [12-14,20]. Fraction of these couplers can react with both blend constituents simultaneously during melt blending to form mixed copolymers. The interfacially formed copolymers tend to anchor along the interface as the result of chemical reaction and serve as effective compatibilizers of blends. Isocyanate $(-\mathrm{NCO})$ group possesses good reactivities with carboxyl $(-\mathrm{COOH})$ and hydroxyl $(-\mathrm{OH})[24]$. The reaction mechanisms of isocyanate with carboxyl and hydroxyl are well established and summarized in Scheme 2 . The reaction proceeds rapidly at high temperature where melt blending is carried out. For PET/PS/SMA/PMPI blends, anhydride group has to undergo ring-opening reaction firstly conducted by a hydroxyl-containing compound as the following equation:

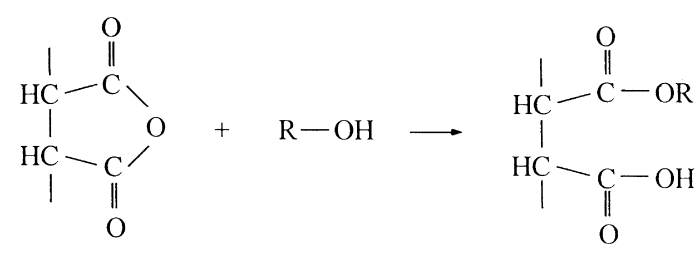

A hydroxyl-containing compound can be obtained from the residual trace water in the blend. Consequently, the reaction between PMPI and SMA can proceed successfully as illustrated in Scheme 2. The isocyanate groups of PMPI can react with the terminal groups of PET ( $-\mathrm{OH}$ and $-\mathrm{COOH}$ ) and the hydroxyl groups of the ring-opened SMA simultaneously to form the desired PET-co-PMPI-co-SMA copolymers during the process of melt blending. These in situ-formed copolymers will locate at the interface preferentially to serve as effective compatibilizers. Certainly, not all the added PMPI is expected to undergo reactions simultaneously with PET and the ring-opened SMA. Portion of the added PMPI may function as a chain extender to react with only one blend component, and such product is unable to serve as a compatibilizer. The efficiency of compatibilization by a coupler depends on the quantity of the mixed copolymers produced. Many factors influence the efficiency of the desired copolymers that can be produced during melt 


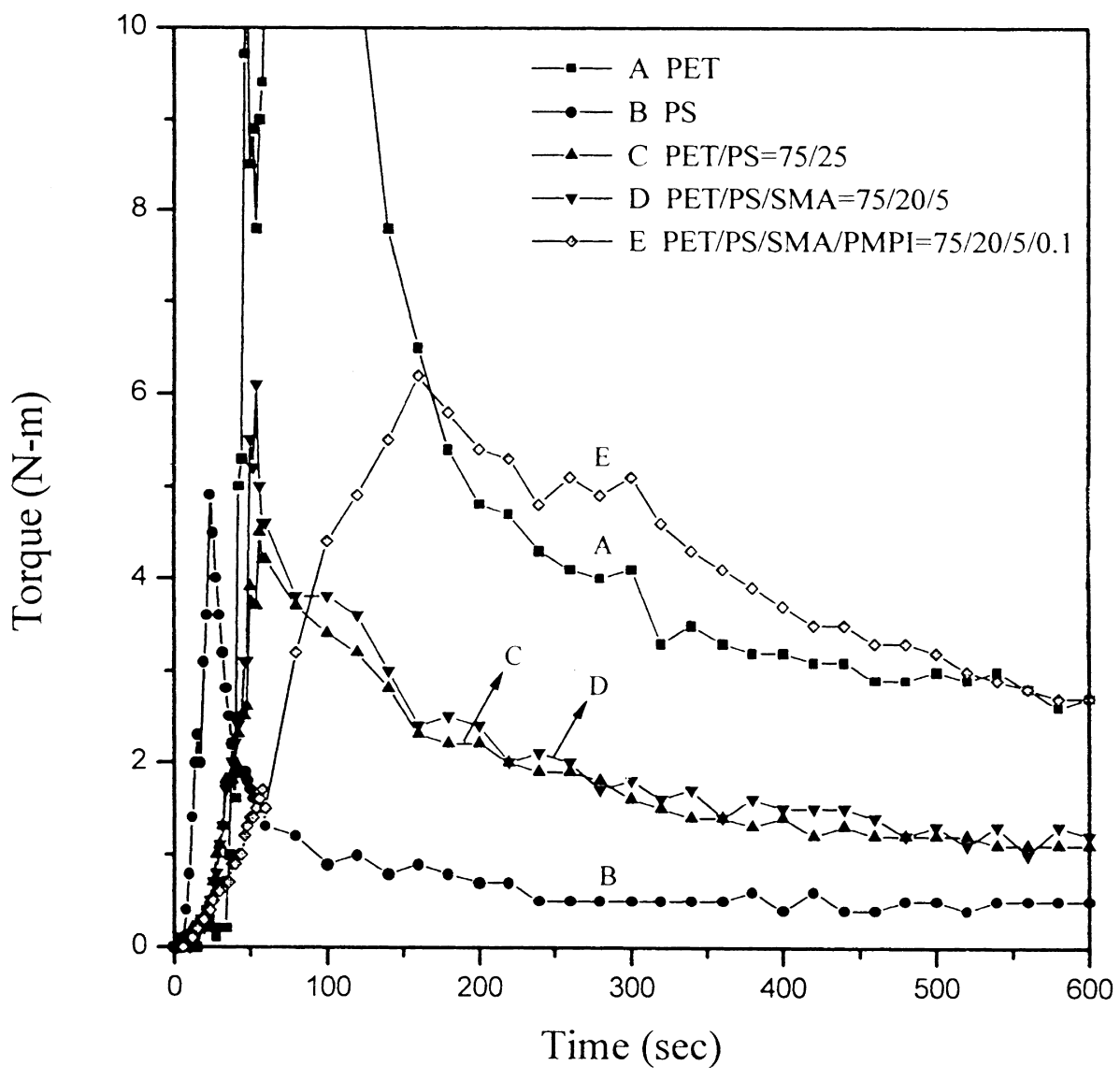

Fig. 1. Plots of torque versus mixing time at $285^{\circ} \mathrm{C}$ and $30 \mathrm{rpm}$.

blending, such as relative reactivity and relative compatibility between the coupler and the constituent components. It is more preferential that this oligomeric isocyanate (PMPI) is incompatible with the constituent components so that PMPI tends to reside at the interface and has better opportunity to contact and react with PET and the ring-opened SMA simultaneously.

\subsection{Rheological properties}

When reactions among functional groups occur, the viscosity of the blend will increase due to the increase of molecular weight. Torque measurement has been utilized successfully to obtain qualitative information concerning the chemical reaction in a reactively compatibilized blend $[20,23]$. The variations of torque values with mixing time for several selected compositions are displayed in Fig. 1. The torque values of the pure PS (Fig. 1(B)) are very low and remain almost constant at $285^{\circ} \mathrm{C}$. At the same test conditions, the torque values of the virginal PET (Fig. 1(A)) are about three times higher than that of PS and decrease with time gradually due to thermal degradation. Torque values of the PET/PS $=75 / 25$ mixture (Fig. 1(C)) lie between that of PET and PS as would be expected. The $\mathrm{PET} / \mathrm{PS} / \mathrm{SMA}=75 / 20 / 5$ mixture gives almost identical torque values to the PET/PS $=75 / 25$ mixture as presented in Fig. 1(D). This result reveals that the reaction between anhydride groups of SMA and hydroxyl groups of PET is unlikely to occur or occurs insignificantly, which means, only secondary physical interaction is expected between PET and SMA in those SMA-containing blends. The noticeable effect of $0.1 \mathrm{phr}$ PMPI on the PET/PS/SMA $=75 / 20 / 5$ mixture is shown in Fig. 1(E), where only $0.1 \mathrm{phr}$ PMPI results in substantial torque increase. The torque value of the PET/PS/SMA/PMPI $=75 / 20 / 5 / 0.1$ mixture is significantly higher than that of the mixture without the presence of PMPI (Fig. 1(D)). The viscosity increase for the PET/PS/ SMA/PMPI mixture is expected and can be attributed to the increase of molecular weight through the coupling reactions as mentioned previously.

The shear viscosity versus shear rate behavior for base polymers and blends at $285^{\circ} \mathrm{C}$ are given in Fig. 2. PET has higher viscosity and less shear thinning than that of PS under the test condition as shown in Fig. 2(A) and (B). Again, the variation of viscosity of the PET/PS $=75 / 25$ blend with shear rates (Fig. 2(C)) lies between that of PET and PS, and the PET/PS/SMA $=75 / 20 / 5$ blend (Fig. 2(D)) exhibits a comparable shear viscosity versus shear rate behavior to the PET/PS $=75 / 25$ blend as would be expected. The observed low viscosity for the 


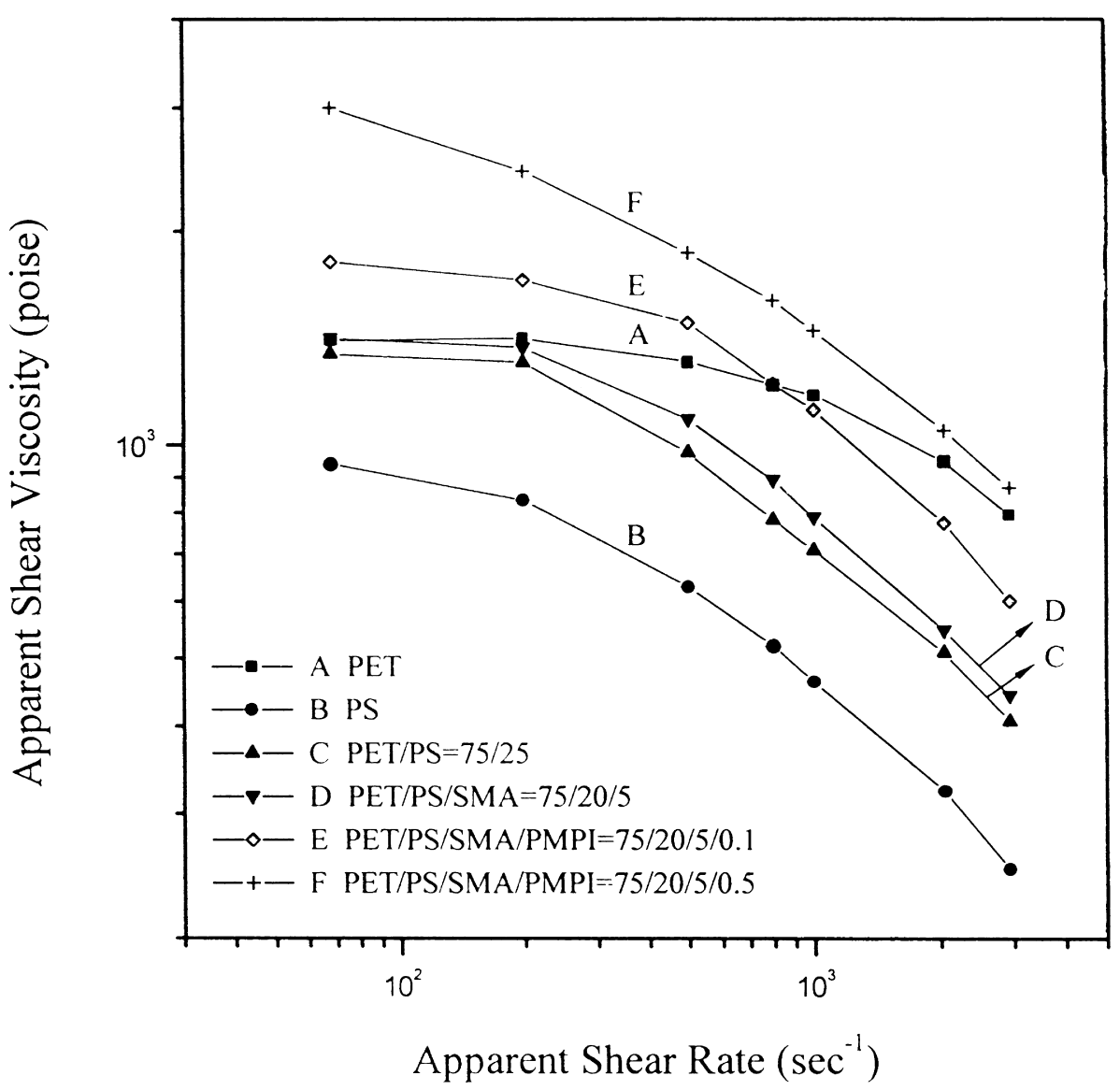

Fig. 2. The variation of shear viscosity with shear rates for base polymers and blends at $285^{\circ} \mathrm{C}$.

PET/PS/SMA $=75 / 20 / 5$ blend indicates that the extent of reaction between anhydride and hydroxyl is unlikely or insignificant during the extruder compounding. This result is consistent with the torque versus time data (Fig. 1). For the compatibilized blends, the presence of $0.1 \mathrm{phr}$ PMPI results in substantial viscosity rise as shown in Fig. 2(E), and the viscosity increases progressively with increasing the amount of PMPI (Fig. 2(F)). The higher viscosity of the better compatibilized blend can be related to the expected higher molecular weight due to the chain extender and coupling reactions. In addition to the expected molecular weight increase, the enhancement of interfacial friction under shear of the compatibilized blends is another reason for the observed higher viscosity. The coupling reaction of PMPI occurs preferentially at the interface, and thus the in situ-formed PET-co-PMPI-co-SMA copolymers tend to anchor along the interface and improve the interfacial adhesion. For the uncompatibilized blends, a "slide" takes place easily between phases of two immiscible homopolymers under shear stress due to high interfacial tension and low interfacial friction and results in lower viscosity. This phenomenon can be observed for the blends with the compositions of PET/PS $=75 / 25$ and PET/PS/SMA $=75 /$ $20 / 5$ as shown in Figs. 1 and 2. The higher interfacial adhesion of the compatibilized blends is able to transfer shear stress effectively, and hence higher viscosity compared with those uncompatibilized blends is observed.

\subsection{Thermal properties}

Figs. 3 and 4 show the DSC cooling and heating scans for the pure PET and blends of PET/PS/SMA $=75 / 20 / 5$ series. Pure PET exhibits a narrower and shaper crystallization exotherm than that of the PET component in blends, uncompatibilized and compatibilized, as shown in Fig. 3(A). Furthermore, it is found that PET components in all compositions are able to crystallize completely under this test condition because the recrystallization of PET has not been observed as shown in Fig. 4. The whole analyzed DSC parameters of pure components, uncompatibilized and compatibilized PET/PS blends are summarized in Table 2 and Figs. 5 and 6 . As the recrystallization of the PET component in all blend compositions has not been observed, the percent of PET crystallinity in a blend is calculated based on the heat of fusion of the PET with $100 \%$ crystallinity at $121.2 \mathrm{~J} / \mathrm{g}$ [25] and expressed as the following equation:

$\%$ PET crystallinity $=\frac{\Delta H_{\mathrm{f}, \mathrm{PET}}}{\Delta H_{\mathrm{f}, \mathrm{PET}}} \times 100 \%$ 


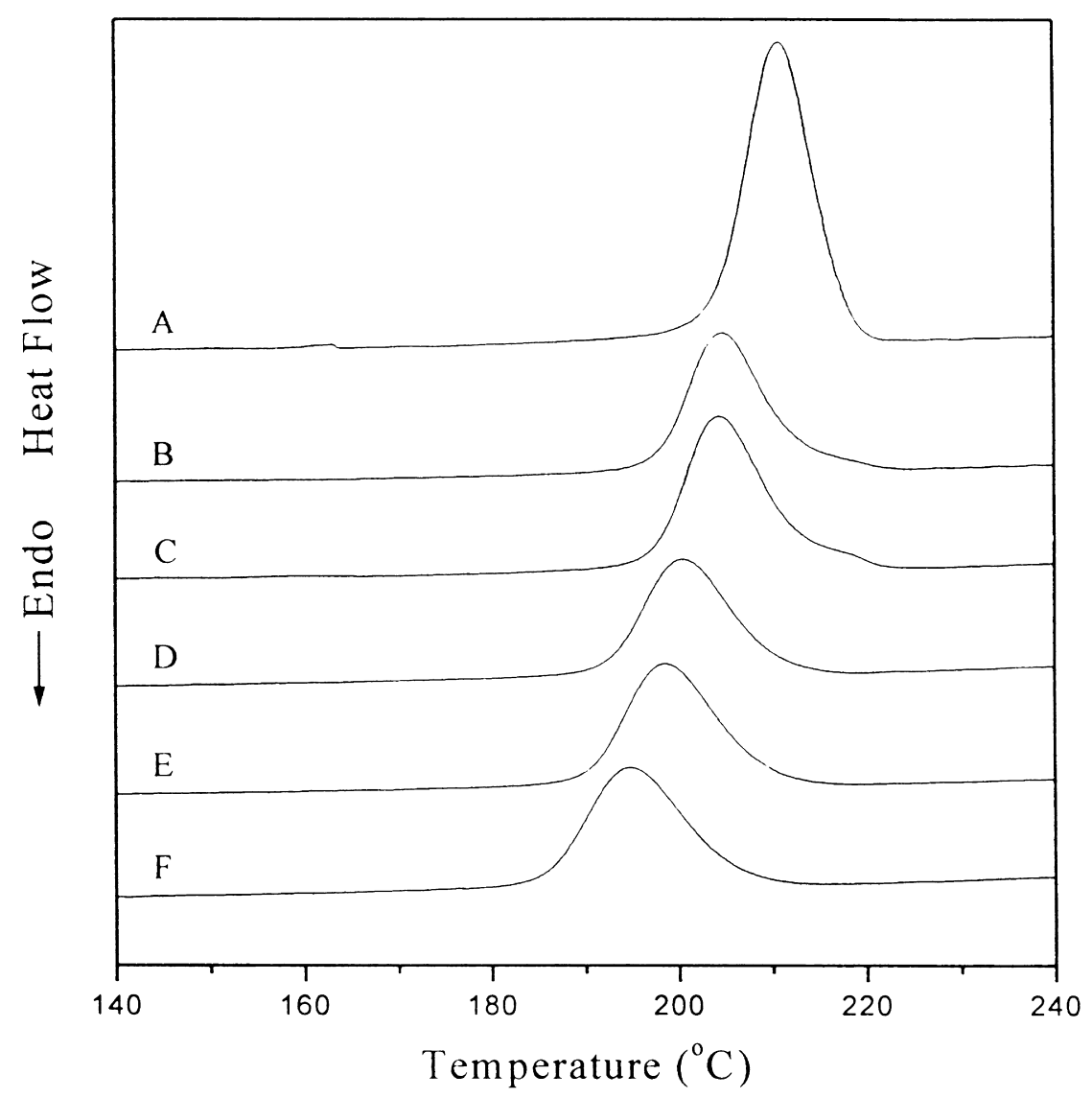

Fig. 3. The cooling scans for pure PET and blends of PET/PS/SMA $=75 / 25 / 5$ series (cooling rate: $10^{\circ} \mathrm{C} / \mathrm{min}$ ). (A) PET, (B) PET/PS $=75 / 25$, (C) PET/PS/ $\mathrm{SMA}=75 / 20 / 5$, (D) PET/PS/SMA/PMPI $=75 / 20 / 5 / 0.1$, (E) PET/PS/SMA/PMPI $=75 / 20 / 5 / 0.3$, (F) PET/PS/SMA/PMPI $=75 / 20 / 5 / 0.5$.

where the heat of fusion, $\Delta H_{\mathrm{f}, \mathrm{PET}}$, of the PET component in blend is measured by DSC, and the $\Delta H_{\mathrm{f}, \mathrm{PET}}^{0}$ is $121.2 \mathrm{~J} / \mathrm{g}$.

Table 2 demonstrates that the amorphous PS possesses a glass transition temperature at $96.8^{\circ} \mathrm{C}\left(T_{\mathrm{g} 2}\right)$. PET is a semicrystalline polymer with a glass transition temperature at $72.4^{\circ} \mathrm{C}\left(T_{\mathrm{g} 1}\right)$ and a melting temperature at $256.6^{\circ} \mathrm{C}$. In all blends, uncompatibilized and compatibilized, the corresponding $T_{\mathrm{g} 1}$ and $T_{\mathrm{g} 2}$ do not shift inward. The distinct glass transition temperatures imply low miscibility of the system that mutual dissolving of PET and PS is negligible even after compatibilization. The PET component in the PET/PS $=75 / 25$ blend exhibits lower crystallization peak temperature $\left(T_{\mathrm{c}}\right)$ and greater crystallization temperature range $\left(\Delta T_{\mathrm{c}}\right)$ than that of pure PET, as shown in Table 2. The $\Delta T_{\mathrm{c}}$ of the PET component in the blend is indicative of the overall crystallization rate. The pure PET has the smallest $\Delta T_{\mathrm{c}}$, which is an indication of the highest crystallization rate. The lower $T_{\mathrm{c}}$ and greater $\Delta T_{\mathrm{c}}$ indicate that the molten PS is able to hinder and retard the crystallization behavior of the PET component in PET/PS $=75 / 25$ blends. $T_{\mathrm{c}}$ and $\Delta T_{\mathrm{c}}$ for the PET component in the PET/PS blends containing 2 and $5 \mathrm{wt}$ \% SMA are comparable to the values obtained for the PET/PS = 75/25 blend. However, when the amount of PMPI is increased in the PET/PS/SMA blends, $T_{\mathrm{c}}$ is depressed and the corresponding $\Delta T_{\mathrm{c}}$ increases significantly as presented in Fig. 5. Evidently, this further reduction of the crystallization rate for the PET component in these compatibilized blends can be attributed to the interfacially formed copolymers. A better compatibilized blend possesses greater number of PET-co-PMPI-co-SMA copolymer molecules anchoring along the interface, and these copolymer molecules are able to hinder the PET from crystallizing, especially in the vicinity of the interface.

Melting parameters of the PET component in blends can manifest the imperfection and size distribution of crystals. The melting peak temperature $\left(T_{\mathrm{m}}\right)$ of the PET component in the compatibilized blends is depressed gradually with the increase of PMPI content, as shown in Fig. 6. Meanwhile, the melting temperature range $\left(\Delta T_{\mathrm{m}}\right)$, which is indicative of crystal imperfection and size distribution, increases with increasing the quantity of compatibilizers (Fig. 6). The copolymer molecules produced at interface prohibit the crystal formation, and result in more imperfect crystals and broaden size distribution. The presence of the in situformed mixed PET-co-PMPI-co-SMA copolymers results in slower crystallization rate, less perfect crystals, and lower crystallinity of the PET component in those compatibilized blends. 


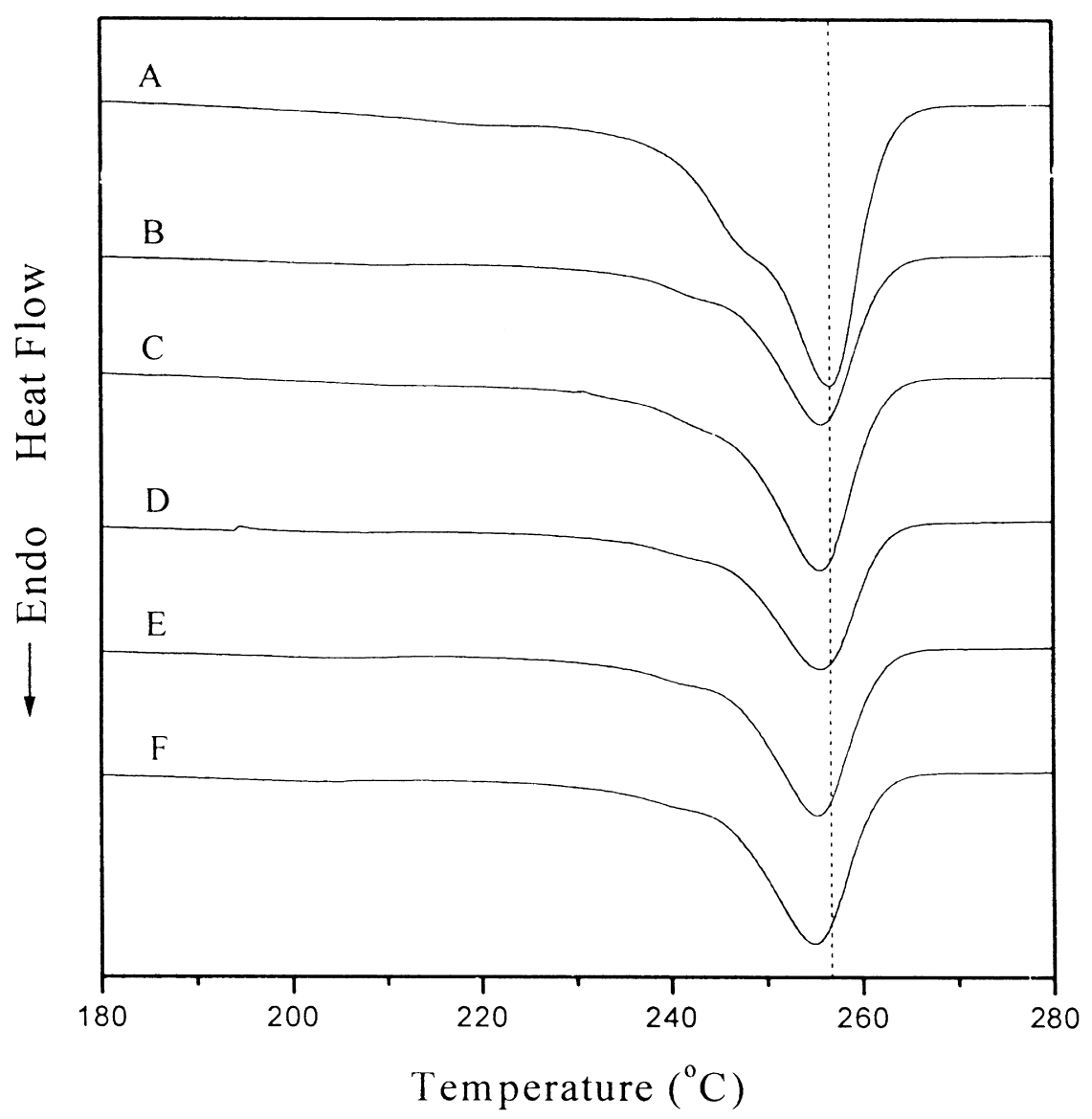

Fig. 4. The heating scans for pure PET and blends of PET/PS/SMA $=75 / 25 / 5$ series (heating rate: $10^{\circ} \mathrm{C} / \mathrm{min}$ ). (A) $\mathrm{PET}$, (B) $\mathrm{PET} / \mathrm{PS}=75 / 25$, (C) $\mathrm{PET} / \mathrm{PS} /$ $\mathrm{SMA}=75 / 20 / 5$, (D) PET/PS/SMA/PMPI $=75 / 20 / 5 / 0.1$, (E) PET/PS/SMA/PMPI $=75 / 20 / 5 / 0.3$, (F) PET/PS/SMA/PMPI $=75 / 20 / 5 / 0.5$.

\subsection{SEM morphologies}

The ultimate goal of compatibilization is to achieve stable phase morphology and improved mechanical performance. Mechanical properties of a heterogeneous polymer blend are directly related to its microstructure, especially the size and shape of the dispersed phase. Fig. 7 presents the SEM micrographs of etched surfaces of PET/PS $=75 / 25$ blends containing various amount of SMA. A coarser morphology can be easily observed in the PET/PS $=75$ / 25 blend because of the incompatibility of these two polymers, as shown in Fig. 7(A). With the presence of SMA in the PET/PS blends, the domain size of the PS dispersed particles does not show substantial reduction, as demonstrated in Fig. 7(B) and (C). This result illustrates that SMA alone cannot efficiently compatibilize polymer blends

Table 2

Summary of thermal properties of PET/PS/SMA/PMPI blends

\begin{tabular}{lllllllll}
\hline Blend Composition & $T_{\mathrm{g} 1}\left({ }^{\circ} \mathrm{C}\right)$ & $T_{\mathrm{g} 2}\left({ }^{\circ} \mathrm{C}\right)$ & $T_{\mathrm{c}}\left({ }^{\circ} \mathrm{C}\right)$ & $\Delta T_{\mathrm{c}}\left({ }^{\circ} \mathrm{C}\right)$ & $T_{\mathrm{m}}\left({ }^{\circ} \mathrm{C}\right)$ & $\Delta T_{\mathrm{m}}\left({ }^{\circ} \mathrm{C}\right)$ & $\Delta H_{\mathrm{f}, \mathrm{PET}}(\mathrm{J} / \mathrm{g})$ & $\%$ PET crystallinity \\
\hline PET & 72.4 & & 210.9 & 28.3 & 256.6 & 40.8 & 47.3 & 39.0 \\
PS & & 96.8 & & & & & & \\
PET/PS = 75/25 & 71.3 & 96.2 & 202.8 & 34.8 & 256.0 & 43.8 & 46.7 & 38.5 \\
PET/PS/SMA/PMPI & & & & & & & & \\
$75 / 23 / 2 / 0$ & 70.9 & 97.8 & 202.4 & 35.3 & 255.9 & 46.0 & 45.3 & 37.4 \\
$75 / 23 / 2 / 0.1$ & 72.1 & 98.2 & 202.1 & 35.7 & 255.5 & 47.3 & 45.3 & 37.4 \\
$75 / 23 / 2 / 0.3$ & 72.0 & 98.6 & 198.6 & 37.1 & 255.2 & 49.8 & 43.5 & 35.9 \\
$75 / 23 / 2 / 0.5$ & 72.4 & 98.1 & 197.2 & 38.0 & 254.7 & 51.1 & 43.7 & 36.1 \\
$75 / 20 / 5 / 0$ & 71.1 & 97.2 & 202.2 & 35.5 & 255.6 & 45.8 & 45.4 & 37.5 \\
$75 / 20 / 5 / 0.1$ & 72.9 & 98.1 & 200.5 & 35.3 & 255.5 & 44.9 & 44.8 & 37.0 \\
$75 / 20 / 5 / 0.3$ & 72.2 & 97.6 & 198.5 & 39.5 & 255.2 & 49.6 & 46.5 & 38.4 \\
$75 / 20 / 5 / 0.5$ & 70.6 & 97.8 & 194.6 & 41.5 & 254.7 & 50.0 & 42.3 & 34.9 \\
\hline
\end{tabular}




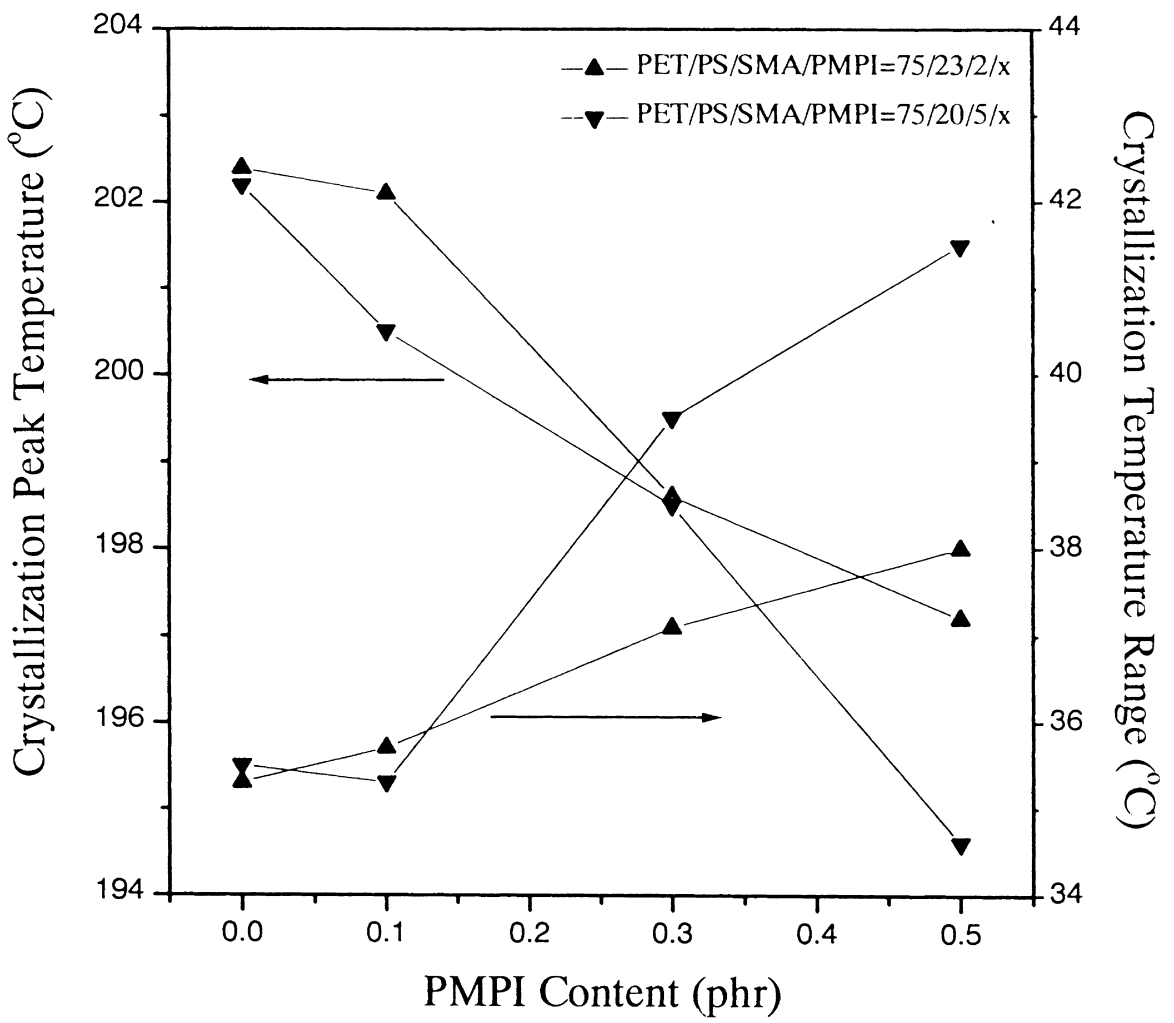

Fig. 5. Variation of the crystallization temperature and its range for the PET component in blends with PMPI content.

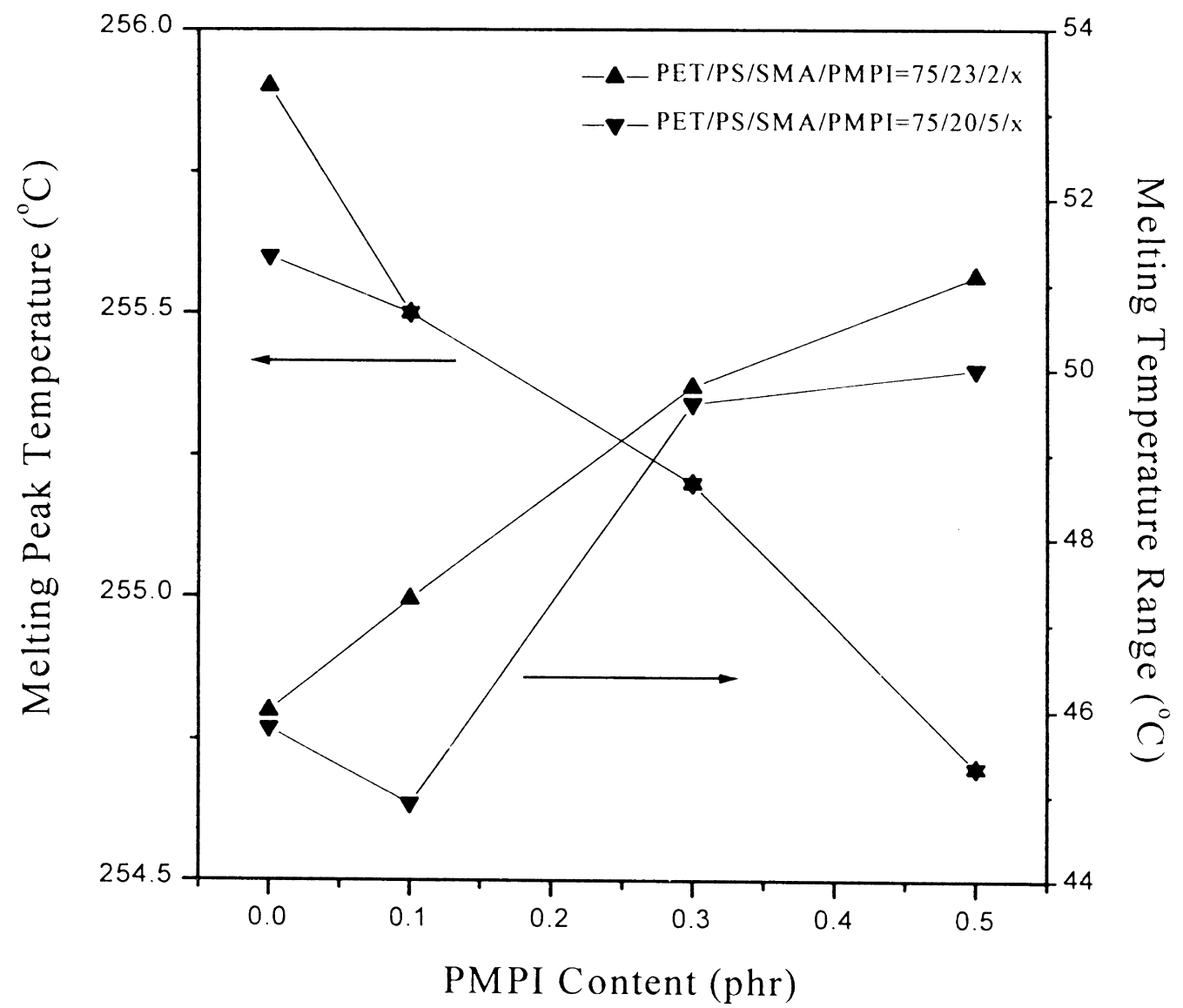

Fig. 6. Variation of the melting temperature and its range for the PET component in blends with PMPI content. 


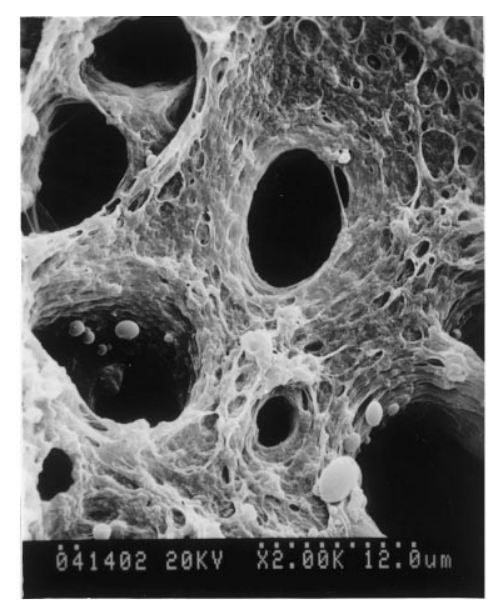

(A) $\mathrm{PET} / \mathrm{PS}=75 / 25$

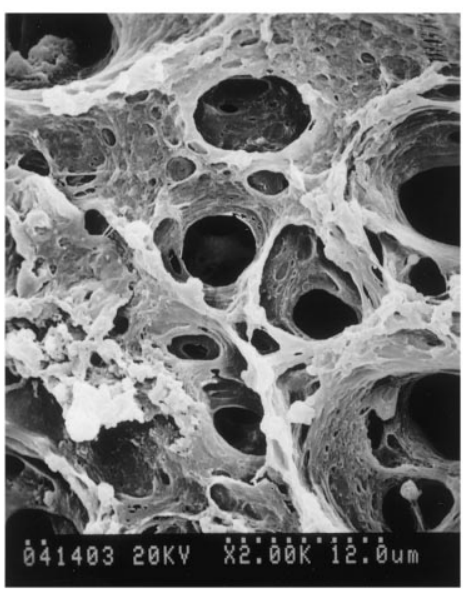

(B) $\mathrm{PET} / \mathrm{PS} / \mathrm{SMA}=75 / 23 / 2$

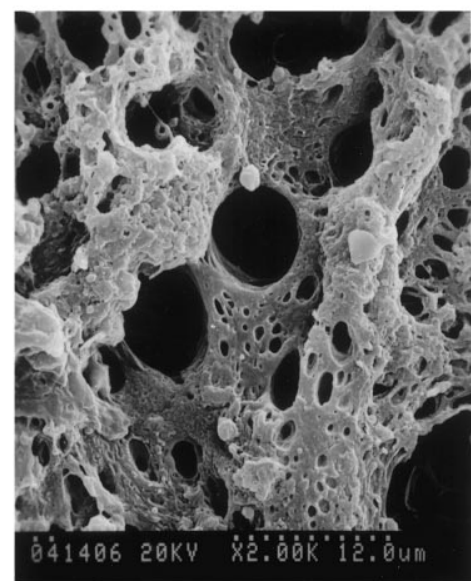

(C) $\mathrm{PET} / \mathrm{PS} / \mathrm{SMA}=75 / 20 / 5$

Fig. 7. SEM micrographs of etched surfaces of PET/PS $=75 / 25$ blends containing various amounts of SMA in the PS phase.

of PET and PS. Finer domain phase morphologies from the compatibilized blends are shown in Fig. 8. It is well known that the major functions of a compatibilizer are to reduce interfacial tension between two immiscible polymers, to permit a finer dispersion during mixing, to provide phase stability against gross segregation upon melt processing, and to broaden interface thickness [26]. A wider interfacial thickness normally reflects a stronger interfacial adhesion and allows for a more efficient stress transfer under stress conditions as well as improved mechanical properties. The formation of the desired PET-co-PMPI-co-SMA copolymers during melt processing leads to lower interfacial tension and phase stabilization against drop coalescence. Therefore, the dispersed PS particle size shows a dramatic reduction and decreases with increasing the quantity of dual compatibilizers (Fig. 8). Those desired copolymers are also responsible for the increase of interfacial adhesion in the solid state. The finer phase domain of the compatibilized blends with higher PMPI content ( $0.5 \mathrm{phr})$ is the evidence of better compatibilization as shown in Fig. 8(B) and (D). Consequently for the incompatible PET/PS blend, the
PET-co-PMPI-co-SMA copolymers serve as compatibilizers that are able to broaden the interfacial thickness so as to induce a higher interfacial adhesion and improve the mechanical properties of the blend.

\subsection{Mechanical properties}

The mechanical properties of the PET/PS $=75 / 25$ blend is less than desirable due to the poor compatibility between PET and PS. Nevertheless, the tensile properties of this incompatible blend can be improved significantly after compatibilization. Figs. 9 and 10 present the tensile properties of PET/PS blends with various amounts of dual compatibilizers. The tensile strength of the compatibilized blends is enhanced progressively with the increase of PMPI content as shown in Fig. 9. On the contrary, the compatibilized blends also exhibit a substantial improvement in tensile elongation (Fig. 10) with increasing the amount of PMPI. Fig. 11 presents the effect of dual compatibilizers content on the unnotched impact strength of PET/PS blends. The general trend is consistent with corresponding tensile 


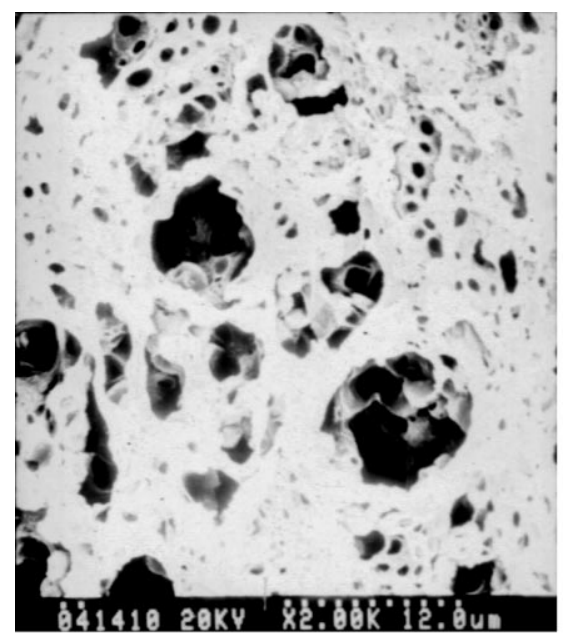

(A) $\mathrm{PET} / \mathrm{PS} / \mathrm{SMA} / \mathrm{PMPI}=75 / 23 / 2 / 0.1$

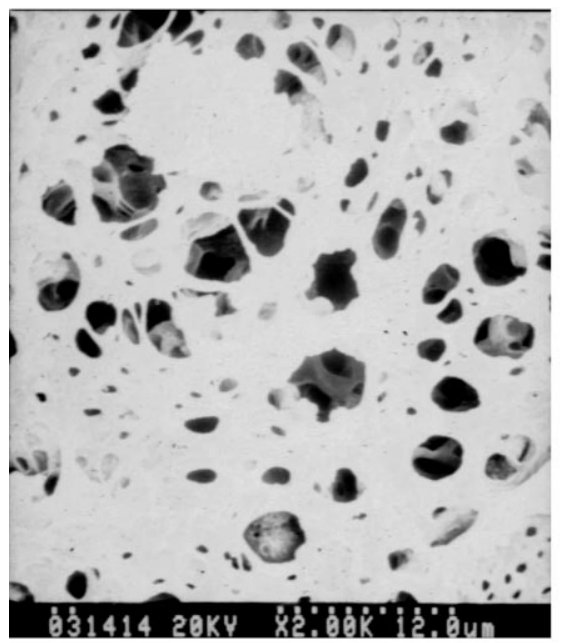

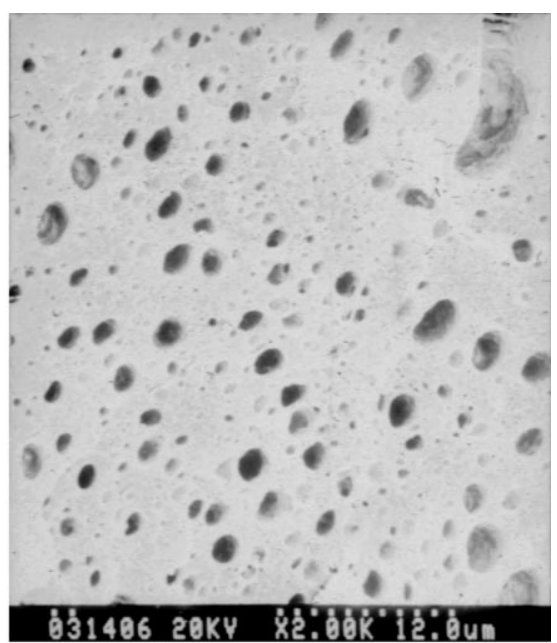

(B) $\mathrm{PET} / \mathrm{PS} / \mathrm{SMA} / \mathrm{PMPI}=75 / 23 / 2 / 0.5$

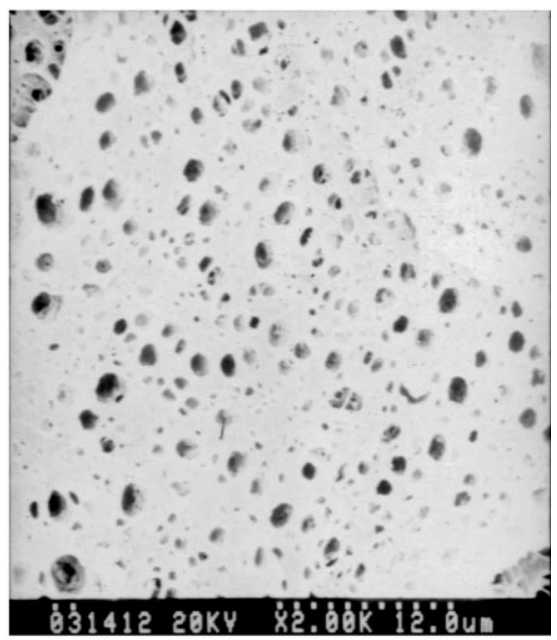

Fig. 8. SEM micrographs of etched surfaces of PET/PS $=75 / 25$ blends containing various amounts of dual compatibilizers as a function of PMPI content.

properties, indicating that dual compatibilizers composed of SMA and PMPI are able to effectively compatibilize the PET/PS blends. Compatibilized blends possess finer phase domain size, greater interfacial contact area, and higher interfacial adhesion than the corresponding uncompatibilized blends as demonstrated in SEM morphologies. The in situ-formed PET-co-PMPI-co-SMA copolymers tend to anchor along the interface, hence, a given stress can be transferred efficiently between phases. A greater number of in situ copolymer molecules are produced with increasing the amounts of SMA and PMPI, resulting in more efficient stress transfer and higher mechanical performance.

\section{Conclusions}

SMA alone cannot be an adequate compatibilizer in blends of PET and PS due to the low reactivity between anhydride and hydroxyl without the presence of a catalyst.
However, the combination of SMA and PMPI has demonstrated to be an effective dual compatibilizer for PET/PS blends. SMA is able to dissolve in the PS phase to make it quasi-functionalized, while the oligomeric PMPI has the chance to react with PET and SMA at the interface simultaneously. Thus, the in situ-formed PET-co-PMPI-co-SMA copolymers will anchor along the interface and serve as excellent compatibilizers. The potential reactions between the terminal groups of PET, maleic anhydride of SMA, and isocyanate of PMPI are confirmed qualitatively by measuring the torque change during melt mixing. The desired copolymers distributed at the interface lead to lower interfacial tension and cause substantial reduction of the dispersed phase domains. Consequently, significant improvements in mechanical performance can be achieved by using this dual compatibilizers, SMA and PMPI. The crystallization behaviors of the PET component in compatibilized blends are also hindered owing to the presence of the in situ-formed mixed copolymer molecules. 


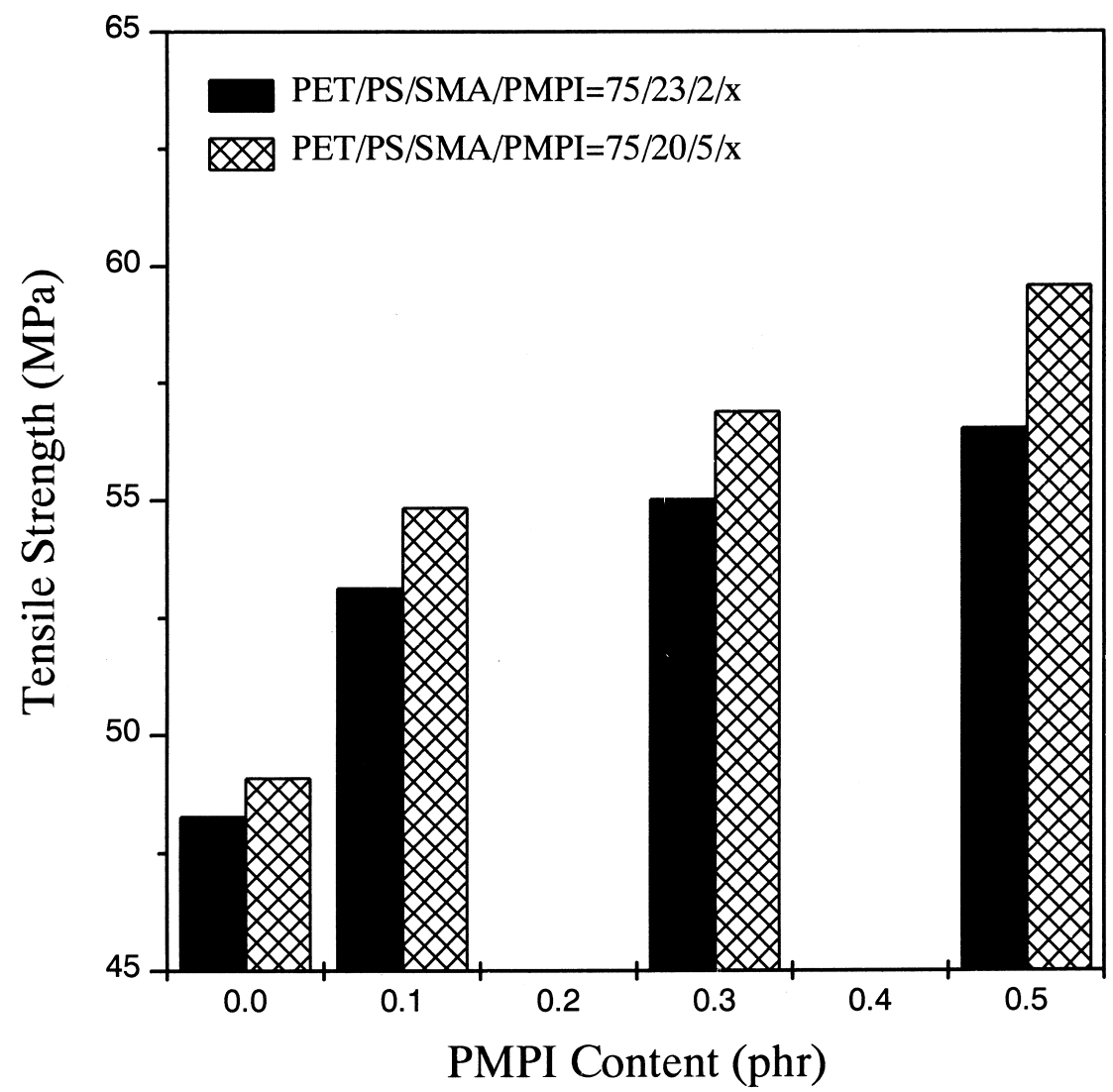

Fig. 9. Effect of the quantity of dual compatibilizers on the tensile strength of PET/PS blends.

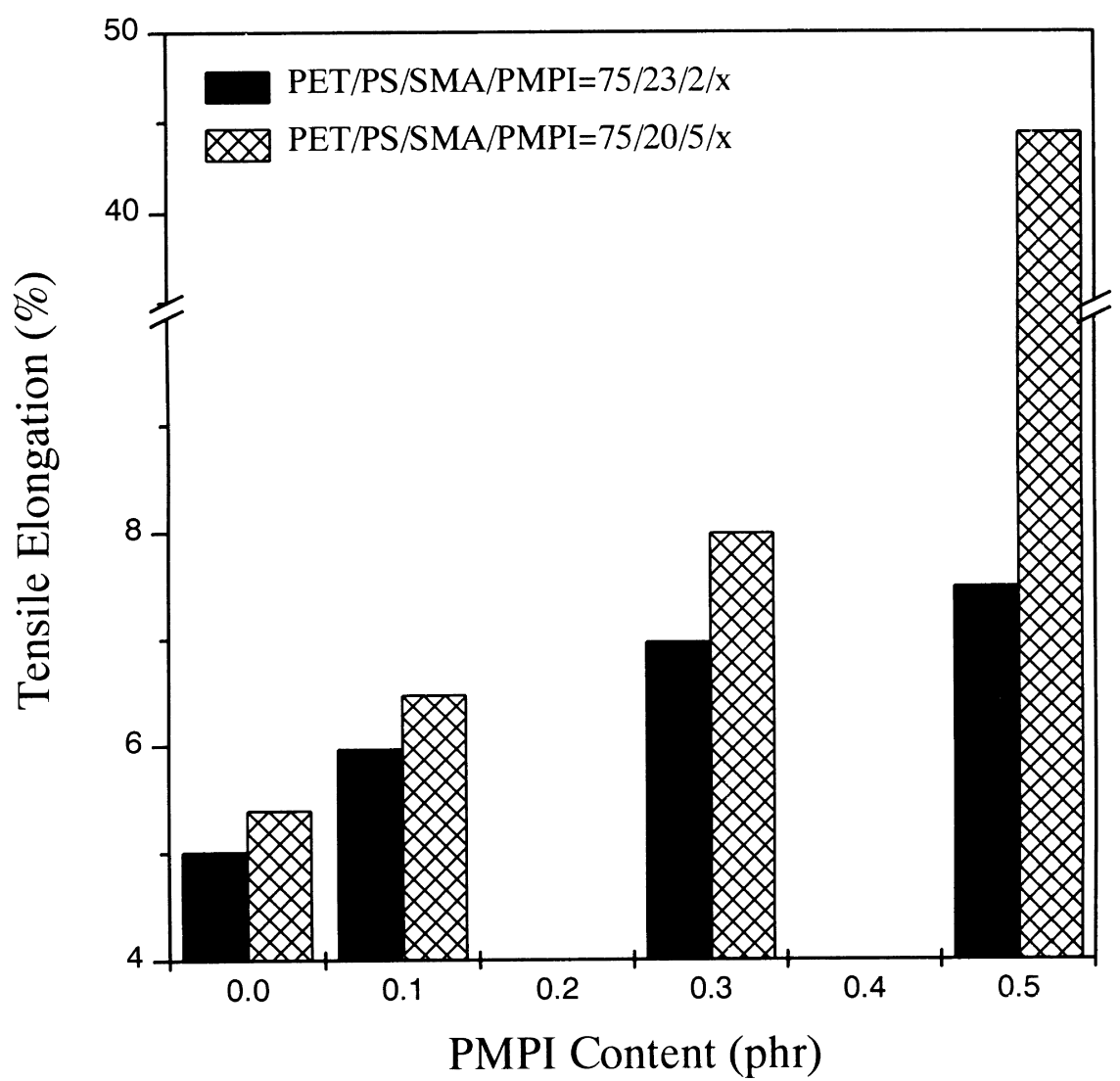

Fig. 10. Effect of the quantity of dual compatibilizers on the tensile elongation of PET/PS blends. 


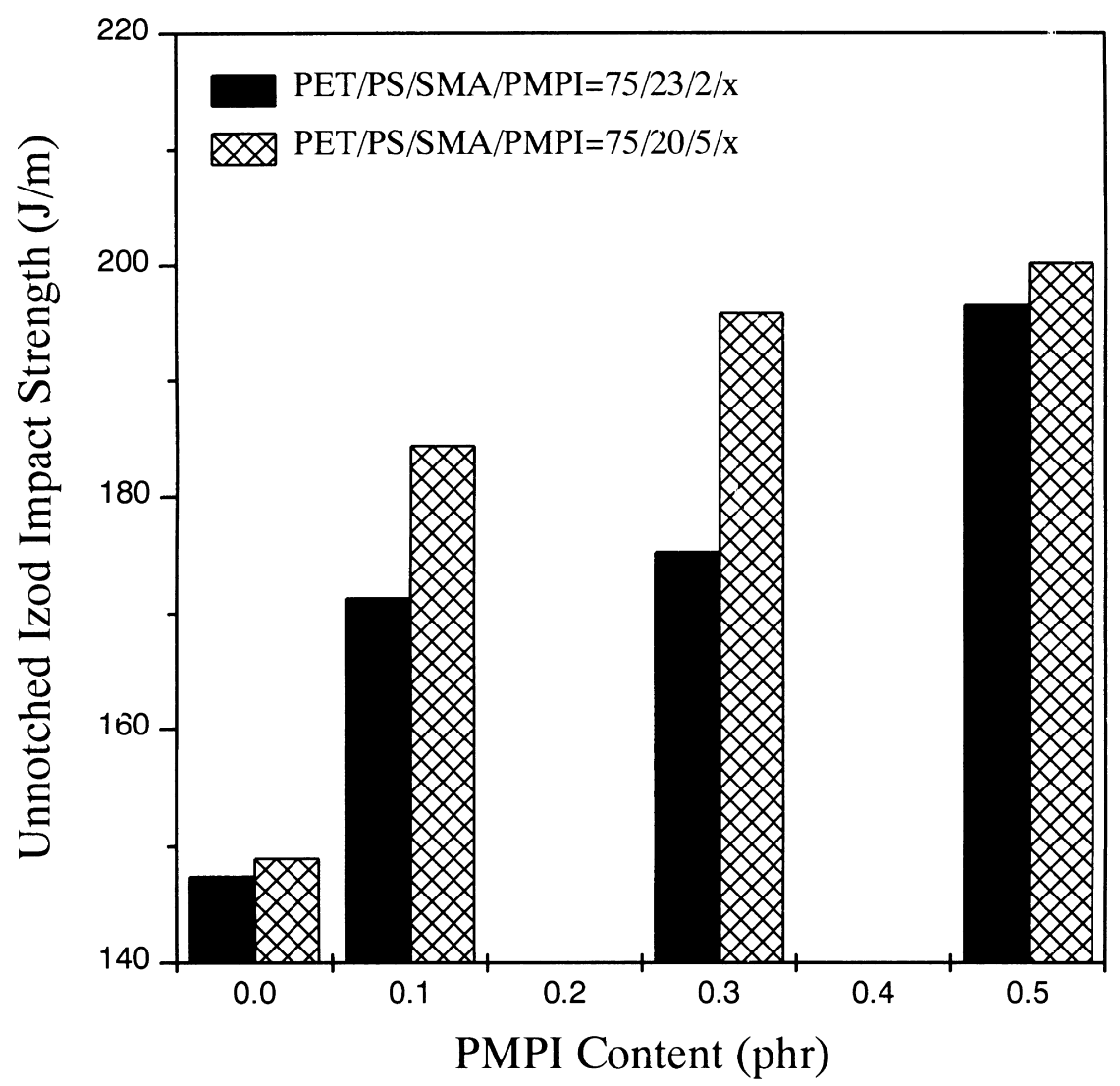

Fig. 11. Effect of the quantity of dual compatibilizers on the impact strength of PET/PS blends.

\section{Acknowledgements}

This research is financially supported by the National Science Council, Taiwan, ROC, under Contract No. NSC87-2216-E-009-006. We thank Shinkong Synthetic Fibers Inc. for donation of materials.

\section{References}

[1] Paul DR, Newman S. Polymer blends, New York: Academic Press, 1978.

[2] Barlow JW, Paul DR. Polym Engng Sci 1984;24:525.

[3] Lyatskaya Y, Balazs AC. Macromolecules 1996;29:7581.

[4] Triacca VJ, Ziaee S, Barlow JW, Keskkula H, Paul DR. Polymer 1991;32:1401.

[5] Park I, Barlow JW, Paul DR. J Polym Sci: Part B: Polym Phys 1992;30:1021.

[6] Majumder B, Keskkula H, Paul DR. Polymer 1994;35:3164.

[7] Chang FC, Hwu YC. Polym Engng Sci 1991;31:1509.

[8] Chiang CR, Chang FC. Polymer 1997;38:4807.
[9] Zhang XM, Yin ZH, Na TH, Yin JH. Polymer 1997;38:5905.

[10] Kim JK, Lee HY. Polymer 1996;37:305.

[11] Maa CT, Chang FC. J Appl Polym Sci 1993;49:913.

[12] Huang CC, Chang FC. Polymer 1997;38:4287.

[13] Chin HC, Chang FC. Polymer 1997;38:2947.

[14] Chiang CR, Chang FC. J Polym Sci: Part B: Polym Phys 1998;36:1805.

[15] Subramamian PM, Mehra V. Polym Engng Sci 1987;27:663.

[16] Bataille P, Boisse S, Schreiber HP. Polym Engng Sci 1987;27:622.

[17] Baker WE, Saleem M. Polym Engng Sci 1987;27:1634.

[18] Worner C, Muller P, Mulhaupt R. J Appl Polym Sci 1997;66:633.

[19] Brown SB. Reactive extrusion. In: Xanthos M, editor. New York: Hanser, 1992 chap. 4.

[20] Ju MY, Chang FC. Submitted for publication.

[21] Pernice P, Berto C, Moro A, Pippa R. US Pat, 1993, 5,210,125.

[22] Koseki T, Sakamoto T, Ito M, Maeda S, Heiuchi T. Jpn Pat, 1987, 62124120.

[23] Chiang CR, Ju MY, Chang FC. Polym Engng Sci 1998;38:622.

[24] Saunders JH, Frisch KC. Polyurethanes: chemistry and technology, New York: Interscience, 1962.

[25] Roberts RC. Polymer 1969;10:113.

[26] Chang FC. Handbook of thermoplastics. In: Olabisi O, editor. New York: Marcel Dekker, 1996 chap. 21. 